\title{
Short communication: Recovery of viable Mycobacterium avium subspecies paratuberculosis from retail pasteurized whole milk in Brazil
}

\author{
I. A. Carvalho, P. A. G. Pietralonga, D. G. G. Schwarz, A. C. S. Faria, and M. A. S. Moreira ${ }^{1}$ \\ Bacterial Diseases Laboratory, Department of Veterinary Medicine, Federal University of Viçosa, Viçosa, Brazil
}

\begin{abstract}
Mycobacterium avium ssp. paratuberculosis (MAP) is the etiological agent of paratuberculosis, a chronic granulomatous enteritis that affects all ruminants worldwide. Some researchers have indicated a possible role of MAP in Crohn's disease. Despite extensive research and large and important advances in the past few decades, the etiology of Crohn's disease remains indefinite. The most probable transmission route of MAP from animals to humans is milk and dairy products. Mycobacterium avium ssp. paratuberculosis has already been detected in milk samples worldwide, and some studies have reported that MAP is resistant to pasteurization. In Brazil, MAP has been reported in raw milk samples; however, Brazilian retail pasteurized milk has not yet been tested for viable MAP. The aim of this study was to investigate MAP in pasteurized milk in the region of Viçosa (Minas Gerais, Brazil). Thirty-seven samples were collected and processed for culture of MAP. One colony similar to MAP was observed and confirmed by IS900-nested PCR and sequencing. Analysis revealed 97 to $99 \%$ identity with the MAP K-10 strain. This study is the first report of the presence of MAP in retail pasteurized whole milk in Brazil.
\end{abstract}

Key words: Mycobacterium avium ssp. paratuberculosis, insertion sequence IS900, polymerase chain reaction, milk

\section{Short Communication}

Mycobacterium avium ssp. paratuberculosis (MAP) is the etiological agent of paratuberculosis, which affects all ruminants (Chiodini et al., 1984). Contamination can occur by the ingestion of milk or food that has been contaminated with feces. It is suspected that MAP is correlated with Crohn's disease, a chronic hu-

Received April 24, 2012.

Accepted August 9, 2012.

${ }^{1}$ Corresponding author: masm@ufv.br man enteritis; thus, the intake of milk with MAP has been considered a potential factor in the transmission of this agent to humans (Over et al., 2011).

Under Brazilian law, milk intended for human consumption must be subjected to heat treatment between 72 and $75^{\circ} \mathrm{C}$ for 15 to $20 \mathrm{~s}$ and then maintained at $4^{\circ} \mathrm{C}$ (Ministério da Agricultura, Pecuária e Abastecimento, 2011). Some researchers have shown that MAP can survive pasteurization conditions (Ellingson et al., 2005), and MAP has already been identified in pasteurized milk in the United Kingdom, United States, Canada, India, and the Czech Republic (Millar et al., 1996; Gao et al., 2002; Ayele et al., 2005; Ellingson et al., 2005; Shankar et al., 2010).

Although Brazil is the fifth largest producer of milk (IBGE, 2010), and MAP has already been detected in raw milk (Carvalho et al., 2009), Brazilian retail pasteurized milk has not yet been tested for viable MAP. The aim of this study was to investigate the presence of viable MAP in retail pasteurized milk in Viçosa (Minas Gerais, Brazil).

From July 2010 to May 2011, 37 plastic bags of cow's milk treated by commercial pasteurization (minimum of $72^{\circ} \mathrm{C}$ for $15 \mathrm{~s}$ ) were obtained at random from supermarkets in Viçosa. Samples were brought directly to the Bacterial Diseases Laboratory, where they were processed. All samples were subjected to the phosphatase test as described previously by Grant et al. (2002a). To obtain a positive control sample of milk, the MAP K-10 strain was inoculated in milk powder (Molico; Nestlé, São Paulo, Brazil) reconstituted with ultrapure water. A negative control sample was also obtained by repeating the same procedure, but without the addition of MAP.

All samples and controls were subjected to the process outlined by Jayarao et al. (2004), with some modifications. Briefly, $40 \mathrm{~mL}$ of each sample was centrifuged for $15 \mathrm{~min}$ at $2,500 \times g$ at room temperature. The resulting pellet was resuspended in $15 \mathrm{~mL}$ of $0.9 \%$ hexadecylpyridinium chloride (Sigma, Mumbai, India). Decontamination was performed overnight, and tubes were then centrifuged again for 15 min at $2,500 \times g$ at room temperature. After centrifugation, the pellet was resuspended in $1 \mathrm{~mL}$ of antimicrobial solution (nalidixic 
acid + vancomycin chloride + amphotericin). A $150-\mu \mathrm{L}$ portion of the resuspended pellet was used to inoculate Herrold's egg yolk medium (HEYM) with and without mycobactin $J$. The incubation period at $37^{\circ} \mathrm{C}$ was 4 mo. Colonies resembling MAP were stained by the ZiehlNeelsen method for the presence of acid-fast bacilli.

Deoxyribonucleic acid was extracted from primary colonies. Briefly, a small loop full of bacteria was suspended in $50 \mu \mathrm{L}$ of ultrapure water in a polypropylene tube. After centrifuging for $5 \mathrm{~min}$ at $16,000 \times g$ at room temperature, the supernatant was discarded and solutions from the Wizard Genomic DNA Purification Kit (Promega, Madison, WI) were added to the bacteria according to the protocol recommended by the manufacturer. To perform the IS900-nested PCR tests, Go Taq Green Master Mix (Promega) was used. The firstround PCR was performed using the following primers: s204 (5'-TGATCTGGACAATGACGGTTACGGA-3') and s749 (5'-CGCGGCACGGCTCTTGTT-3'), which amplified a fragment of $563 \mathrm{bp}$. The nested PCR was performed using the primers s347 (5'-GCCGCGCTGCTGGAGTTGA-3') and s535 (5'-AGCGTCTTTGGCGTCGGTCTTG-3'), which amplified an internal fragment of $210 \mathrm{bp}$ (Englund et al., 1999). Polymerase chain reaction tests were performed according to the authors' recommendations. Ultrapure water and the MAP K-10 strain were used as negative and positive controls, respectively, and a 100-bp DNA ladder (Invitrogen, Washington, DC) was used as a molecular marker.

To confirm the identity of the amplified fragments (210 bp), the amplicons were purified using a Wizard Plus SV Miniprep DNA Purification System Kit (Promega) sequenced in triplicate in both directions, and the obtained sequences were aligned, edited, and compared with other sequences deposited in GenBank by using Basic Local Alignment Search Tool (BLAST) software (http://www.ncbi.nlm.nih.gov).

In 1 of the $37(2.7 \%)$ analyzed samples of commercially pasteurized milk, suspected MAP colonies (based on colony morphology) were detected on HEYM with mycobactin $J$, and no colonies were observed on HEYM without mycobactin $J$. Microscopically, colonies were found to consist of typical Ziehl-Neelsen-positive acid-fast bacilli showing characteristic clumping. All commercially pasteurized retail milk samples tested phosphatase negative.

The IS900-nested PCR was positive for these colonies. The fragment of $210 \mathrm{bp}$ was sequenced and the genetic analysis revealed 97 to $99 \%$ identity between the amplified sequence and the MAP strain K-10 sequence available in the National Center for Biotechnology Information database.
Mycobacterium avium ssp. paratuberculosis may be cultured from milk after HTST pasteurization if the organism is present in raw milk in sufficient numbers (Millar et al., 1996; Grant et al., 1998, 2002b). In Brazil, no studies have been conducted on the enumeration of MAP in raw milk samples, and studies on paratuberculosis in this country are only beginning to appear.

The detection of viable MAP in retail milk destined for consumers in Viçosa is further confirmatory evidence that this microorganism can survive the minimum HTST pasteurization temperatures accepted by Brazilian legislation. Taken together, the results of research from several countries confirm that human populations are exposed to this chronic enteric pathogen in retail milk supplies (Grant et al., 2002a; Ayele et al., 2005).

The successful recovery of MAP from milk samples depends on many factors, such as the number of MAP organisms in the original sample, the differences between strains, the effect of hexadecylpyridinium chloride decontamination on MAP viability, the antagonistic interference from non-acid-fast microorganisms during incubation, and others (Dundee et al., 2001; O'Reilly et al., 2004). Thus, a risk of false-negative results exists, as well as a lower culture detection rate of MAP in milk treated by small-scale and commercial pasteurization. Therefore, although the culture detection rate of MAP in this study is comparable with rates from the Czech Republic (1.6\%) and the United Kingdom (2\%), it can be underestimated (Grant et al., 2002a; Ayele et al., 2005).

Mycobacterium avium ssp. paratuberculosis detection peaks were observed in many studies (Millar et al., 1996; Grant et al., 2002a; O'Reilly et al., 2004), and this study was designed with sample collection for a year to enable observation of these peaks. However, MAP detection was observed in only 1 sample. Thus, it was not possible to make inferences about peaks of MAP detection in Brazil.

The most effective way of reducing any potential human health risk of exposure to MAP through the consumption of cow's milk is to control paratuberculosis in the national dairy herd (O'Reilly et al., 2004). However, in Brazil no national program has yet been established for the control of paratuberculosis.

This study provides evidence that MAP is present in commercial pasteurized milk in the state of Minas Gerais and in Brazil. In other words, it is further confirmatory evidence that this microorganism can survive the minimum HTST pasteurization temperatures outlined by the legislation. This result has important implications because human exposure to MAP is a potential risk for Crohn's disease. This is the first report of viable MAP in retail pasteurized whole milk in Brazil. 


\section{ACKNOWLEDGMENTS}

The authors thank Coordenação de Aperfeiçoamento de Pessoal de Nível Superior (CAPES, Brasília, Distrito Federal, Brazil), Fundação de Amparo à Pesquisa do Estado de Minas Gerais (FAPEMIG, Belo Horizonte, Minas Gerais, Brazil), and Conselho Nacional de Desenvolvimento Científico e Tecnológico (CNPq, Brasília, Distrito Federal, Brazil) for financial support and Yung-Fu Chang, from Cornell University (Ithaca, NY), for intellectual contributions and support.

\section{REFERENCES}

Ayele, W. Y., P. Svastova, P. Roubal, M. Bartos, and I. Pavlik. 2005. Mycobacterium avium subspecies paratuberculosis cultured from locally and commercially pasteurized cow's milk in the Czech Republic. Appl. Environ. Microbiol. 71:1210-1214.

Carvalho, I. A., A. Silva Jr., V. E. Campos, and M. A. Moreira. 2009. Short communication: Detection of Mycobacterium avium subspecies paratuberculosis by polymerase chain reaction in bovine milk in Brazil. J. Dairy Sci. 92:5408-5410.

Chiodini, R. J., H. J. Van Kruiningen, and R. S. Merkal. 1984. Ruminant paratuberculosis (Johne's disease): The current status and future prospects. Cornell Vet. 74:218-262.

Dundee, L., I. R. Grant, H. J. Ball, and M. T. Rowe. 2001. Comparative evaluation of four decontamination protocols for the isolation of Mycobacterium avium ssp. paratuberculosis from milk. Lett. Appl. Microbiol. 33:173-177.

Ellingson, J. L., J. L. Anderson, J. J. Koziczkowski, R. P. Radcliff, S. J. Sloan, S. E. Allen, and N. M. Sullivan. 2005. Detection of viable Mycobacterium avium ssp. paratuberculosis in retail pasteurized whole milk by two culture methods and PCR. J. Food Prot. 68:966-972.

Englund, S., A. Ballagi-Pordany, G. Bolske, and K. E. Johansson. 1999. Single PCR and nested PCR with a mimic molecule for detection of Mycobacterium avium ssp. paratuberculosis. Diagn. Microbiol. Infect. Dis. 33:163-171.

Gao, A., L. Mutharia, S. Chen, K. Rahn, and J. Odumeru. 2002. Effect of pasteurization on survival of Mycobacterium paratuberculosis in milk. J. Dairy Sci. 85:3198-3205.

Grant, I. R., H. Ball, and M. T. Rowe. 2002a. Incidence of Mycobacterium paratuberculosis in bulk raw and commercially pasteurized cows' milk from approved dairy processing establishments in the United Kingdom. Appl. Environ. Microbiol. 68:2428-2435.

Grant, I. R., H. J. Ball, and M. T. Rowe. 1998. Effect of high-temperature, short-time (HTST) pasteurization on milk containing low numbers of Mycobacterium paratuberculosis. Lett. Appl. Microbiol. 26:166-170.

Grant, I. R., E. I. Hitchings, A. McCartney, F. Ferguson, and M. T. Rowe. 2002b. Effect of commercial-scale high-temperature, shorttime pasteurization on the viability of Mycobacterium paratuberculosis in naturally infected cows' milk. Appl. Environ. Microbiol. 68:602-607.

IBGE (Instituto Brasileiro de Geografia e Estatística). 2010. Subject: Produção da Pecuária Municipal. Accessed Nov. 22, 2011. http:// www.ibge.gov.br/home/estatistica/economia/ppm/2010/default_ pdf.shtm.

Jayarao, B. M., S. R. Pillai, D. R. Wolfgang, D. R. Griswold, C. A. Rossiter, D. Tewari, C. M. Burns, and L. J. Hutchinson. 2004. Evaluation of IS900-PCR assay for detection of Mycobacterium avium subspecies paratuberculosis infection in cattle using quarter milk and bulk tank milk samples. Foodborne Pathog. Dis. $1: 17-26$.

Millar, D., J. Ford, J. Sanderson, S. Withey, M. Tizard, T. Doran, and J. Hermon-Taylor. 1996. IS 900 PCR to detect Mycobacterium paratuberculosis in retail supplies of whole pasteurized cows' milk in England and Wales. Appl. Environ. Microbiol. 62:3446-3452.

Ministério da Agricultura, Pecuária e Abastecimento. 2011. Instrução Normativa no. 62, de 29 de dezembro. Ministério da Agricultura, Pecuária e Abastecimento, Brasília, Distrito Federal, Brazil.

O'Reilly, C. E., L. O'Connor, W. Anderson, P. Harvey, I. R. Grant, J. Donaghy, M. Rowe, and P. O'Mahony. 2004. Surveillance of bulk raw and commercially pasteurized cows' milk from approved Irish liquid-milk pasteurization plants to determine the incidence of Mycobacterium paratuberculosis. Appl. Environ. Microbiol. 70:5138-5144.

Over, K., P. G. Crandall, C. A. O'Bryan, and S. C. Ricke. 2011. Current perspectives on Mycobacterium avium ssp. paratuberculosis, Johne's disease, and Crohn's disease: A review. Crit. Rev. Microbiol. 37:141-156.

Shankar, H., S. V. Singh, P. K. Singh, A. V. Singh, J. S. Sohal, and R. J. Greenstein. 2010. Presence, characterization, and genotype profiles of Mycobacterium avium subspecies paratuberculosis from unpasteurized individual and pooled milk, commercial pasteurized milk, and milk products in India by culture, PCR, and PCR-REA methods. Int. J. Infect. Dis. 14:121-e126. 